\title{
Intake and status of folate and related B-vitamins: considerations and challenges in achieving optimal status
}

\author{
Helene McNulty ${ }^{1}$ and John M. Scott ${ }^{2} *$ \\ ${ }^{1}$ The Northern Ireland Centre for Food and Health (NICHE), School of Biomedical Sciences, University of Ulster, \\ Coleraine BT52 1SA, Northern Ireland \\ ${ }^{2}$ Department of Immunology and Biochemistry, Trinity College, Dublin 2, Ireland
}

Folate and the metabolically related B-vitamins, vitamin $\mathrm{B}_{12}$ and riboflavin, have attracted much scientific and public health interest in recent years. Apart from a well established role in preventing neural tube defects (NTDs), evidence is emerging to support other potential roles for folate and/or related B-vitamins in protecting against cardiovascular disease (especially stroke), certain cancers, cognitive impairment and osteoporosis. However, typical folate intakes are sub-optimal, in that although adequate in preventing clinical folate deficiency (i.e. megaloblastic anaemia) in most people, they are generally insufficient to achieve a folate status associated with the lowest risk of NTDs. Natural food folates have a limited ability to enhance folate status as a result of their poor stability under typical cooking conditions and incomplete bioavailability when compared with the synthetic vitamin, folic acid (as found in supplements and fortified foods). Current folate recommendations to prevent NTDs (based primarily on folic acid supplementation) have been found to be ineffective in several European countries. In contrast, in North America and Chile, the policy of mandatory folic acid-fortification has proven itself in terms of lowering the prevalence of NTD, but remains controversial because of concerns regarding potential risks of chronic exposure to high-dose folic acid. In the case of vitamin $B_{12}$, the achievement of an optimal status is particularly difficult for many older people because of the common problem of food-bound $\mathrm{B}_{12}$ malabsorption. Finally, there is evidence that riboflavin status is generally low in the UK population, and particularly so in younger women; this warrants further investigation.

Folate: Vitamin $\mathbf{B}_{12}$ : Vitamin $\mathbf{B}_{2}$ (riboflavin): Homocysteine

In recent years there has been a growing interest in folate and the metabolically related B-vitamins (vitamin $\mathrm{B}_{12}$, vitamin $\mathrm{B}_{6}$ and riboflavin). Apart from a well established role in the prevention of neural tube defects (NTDs), an optimal status of folate and related B-vitamins may protect against cardiovascular disease (particularly stroke) and certain cancers, and may have other important roles in cognitive function and bone health. These effects may/may not be mediated via homocysteine, the metabolism of which requires an adequate status of all four relevant B-vitamins. However, in the case of folate, vitamin $\mathrm{B}_{12}$ and riboflavin, the achievement of an optimal status presents particular challenges. This review will consider these nutrients, their potential roles in disease prevention, the assessment of status and the challenges involved in achievement of an optimal nutritional status.

\section{Folate}

Folate has a major role in one-carbon metabolism, involving the transfer and utilisation of one-carbon units in DNA and RNA biosynthesis, methylation reactions and amino acid metabolism. Folate deficiency leads to megaloblastic anaemia, characterised by larger than normal red cell precursors (megaloblasts) in bone marrow, macrocytes in the peripheral blood and giantism in the morphology of proliferating cells.
Folate status is routinely assessed by measurement of folate concentrations in plasma/serum or red cells. Red cell folate is considered to be the best index of longer term status (i.e. over the previous months), while serum folate reflects more recent dietary intake. The measurement of plasma total homocysteine concentration provides a reliable functional marker of folate status, on the basis that normal homocysteine metabolism requires an adequate supply of folate. When folate status is low or deficient, elevated plasma homocysteine is invariably observed.

Typical folate intakes are found to be sub-optimal in the diets of many people when considered from the perspective of achieving an optimal folate status, i.e. a folate level associated with lowest risk of folate-related disease (e.g. NTDs), rather than merely preventing overt folate deficiency (i.e. megaloblastic anaemia). This widespread under-provision of folate is generally attributed to the poor bioavailability of natural food folates. Although there is general agreement among experts that the bioavailability of natural food folates is incomplete when compared with the synthetic vitamin folic acid (FA), reported estimates of relative bioavailability vary greatly among human studies ${ }^{(1)}$.

With such uncertainty regarding folate bioavailability from food, setting dietary folate recommendations is problematic for policy makers. The approach adopted in the United States $^{(2)}$ is based on an adjustment for the differences in 
bioavailability between natural food folates and the synthetic vitamin, with the introduction of 'Dietary Folate Equivalents' (DFE). The DFE is defined as the quantity of natural food folate plus 1.7 times the quantity of FA in the diet, a definition based on the assumption that the bioavailability of FA added to food is greater than that of natural food folate by a factor of 1.7. This estimation, however, is highly dependent on one metabolic study in non-pregnant women which estimated the bioavailability of food folates to be no more than $50 \%$ relative to that of $\mathrm{FA}^{(3)}$, plus other evidence showing that FA added to food had about $85 \%$ the bioavailability of free $\mathrm{FA}^{(4)}$. Subsequent bioavailability studies have addressed the robustness of the US DFE value, with the findings of some ${ }^{(5)}$ being generally supportive of the estimates used, whereas others have concluded that food folate bioavailability is far greater than that assumed in generating the US DFE ${ }^{(6)}$. Emerging dietary folate recommendations in other countries may adopt a similar approach to that used in the United States, and the folate bioavailability literature will need to be carefully considered. Apart from their poor bioavailability, natural food folates (particularly green vegetables) can be unstable under typical cooking conditions, and this can substantially reduce the vitamin content before it is even ingested $^{(1)}$. This is an important (but often overlooked) additional factor limiting the ability of natural food folates to enhance folate status. In contrast to food folates, FA (as found in supplements and fortified foods) provides a very stable and highly bioavailable form of the vitamin.

\section{Vitamin $B_{12}$}

Vitamin $\mathrm{B}_{12}$ is required as a cofactor for two mammalian enzymes: methionine synthetase and methylmalonyl CoA mutase. In vitamin $B_{12}$ deficiency, reduced function of the latter enzyme causes levels of the substrate methylmalonylCoA to build up and form the by-product methylmalonic acid (MMA) which is then excreted into the circulation; plasma MMA is thus a functional marker that is specific to vitamin $\mathrm{B}_{12}$ and will not be affected by intake/status of other B-vitamins. In the other reaction, vitamin $\mathrm{B}_{12}$ (as methylcobalamin) acts as a cofactor for methionine synthetase which catalyzes the remethylation of homocysteine to methionine. However this metabolic step is not only dependent on vitamin $B_{12}$ but also on folate. Measurement of plasma homocysteine can therefore provide a functional biomarker of vitamin $\mathrm{B}_{12}$ status, but it is not specific for vitamin $B_{12}$ and will be principally affected by changes in folate status (and also by vitamin $\mathrm{B}_{6}$ ).

Measurement of serum/plasma total vitamin $B_{12}$ concentrations is the standard screening test for vitamin $B_{12}$ deficiency, but it may not be the most sensitive marker of $\mathrm{B}_{12}$ status $^{(7)}$. It is proposed that the most relevant measure of vitamin $B_{12}$ status is holotranscobalamin (holoTC) as this represents the fraction of circulating $B_{12}$ that is attached to transcobalamin, the protein that delivers vitamin $\mathrm{B}_{12}$ to cells. In recent years, a reliable method to measure holoTC using a radio immuno-assay (RIA) was developed and validated $^{(8)}$. Numerous studies have since been published, strongly suggesting that holoTC may be a more reliable marker of $\mathrm{B}_{12}$ status than the typically used marker of status, serum total $\mathrm{B}_{12}$ concentration. The method has been the basis of an EU project framework 5 QLRT-2001-01775 "Demonstration of the clinical utility of holoTC as an early marker of vitamin $\mathrm{B}_{12}$ deficiency" aimed at determining the clinical utility of holoTC as a marker of vitamin $B_{12}$ deficiency ${ }^{(9)}$. Some preliminary data from this project have been published, confirming that holoTC may be a better marker of $\mathrm{B}_{12}$ status than serum total $\mathrm{B}_{12}$ concentration ${ }^{(10)}$.

There is a high prevalence of low/deficient vitamin $B_{12}$ status among healthy elderly people which becomes more common with increasing age. One recent population-based study estimated that as many as $10 \%$ and $20 \%$ of British people aged $65-74$ and $>75 \mathrm{y}$, respectively, were at high risk of vitamin $\mathrm{B}_{12}$ deficiency ${ }^{(11)}$. In other studies the prevalence of mild vita$\min \mathrm{B}_{12}$ deficiency is reported to be as high as $45 \%$, depending on the diagnostic criteria used ${ }^{(12)}$. However, the low status of $B_{12}$ found in older people is not explained by inadequate dietary intakes of vitamin $\mathrm{B}_{12}$. In fact, among older adults living in the UK, the average daily intake of vitamin $\mathrm{B}_{12}$ was found to be $5.2 \mu \mathrm{g} / \mathrm{d}$, an intake which is at least as good as that found in younger adults ${ }^{(13)}$ and markedly higher than the reference nutrient intake (RNI) value of $1.5 \mu \mathrm{g} / \mathrm{d}$. Thus, the average diet of older people provides vitamin $\mathrm{B}_{12}$ levels which appear to be well in excess of needs.

The high prevalence of vitamin $\mathrm{B}_{12}$ deficiency among older people, despite adequate intakes, relates to changes in the gut with age that may prevent its release from natural food sources. Absorption of vitamin $\mathrm{B}_{12}$ from food requires the action of the stomach, pancreas, and small intestine and is therefore dependent upon normal functioning throughout the gastrointestinal tract. Less than $2 \%$ of cases of $B_{12}$ deficiency can be explained by pernicious anaemia, a condition characterised by loss of secretion of gastric intrinsic factor (GIF) leading to very marked $\mathrm{B}_{12}$ depletion as the vitamin must bind to GIF in order to be absorbed in the terminal ileum $^{(14)}$. To effectively treat pernicious anaemia, therefore, patients must be given regular $B_{12}$ injections which are continued for life. However, a much more prevalent but largely unrecognised cause of mild $\mathrm{B}_{12}$ deficiency is considered to be food-bound malabsorption. This is mainly caused by atrophic gastritis, an age-related condition resulting in decreased gastric acid production (hypochlorhydria). Because gastric acid is required for the release of vitamin $B_{12}$ from proteins in food, vitamin $\mathrm{B}_{12}$ absorption from foods is diminished in older people with hypochlorhydria ${ }^{(14)}$. In theory, older adults with mild (pre-clinical) $\mathrm{B}_{12}$ deficiency due to foodbound malabsorption should be able to absorb free (crystalline) vitamin $B_{12}$ because it is not bound to protein and because intrinsic factor is still secreted. In fact, on the basis of this assumption, the Institute of Medicine in the $\mathrm{US}^{(2)}$ recommends that people aged 50 years and over consume most of their vitamin $B_{12}$ from crystalline $B_{12}$ found in fortified foods and supplements. No such recommendation exists in the UK and no study to date has directly addressed this issue in order to provide a firm basis for introducing one.

The issue of low/deficient $\mathrm{B}_{12}$ status among older people is also relevant to emerging policy on mandatory fortification of food with FA. A number of European countries have opted not to proceed with mandatory fortification or have delayed a decision on it because of potential health risks to the elderly, primarily the concern that high dose FA might mask the anaemia of vitamin $B_{12}$ deficiency in older people, while allowing 
the associated irreversible neurological symptoms to progress ${ }^{(15)}$. Although some reports concluded that mandatory FA fortification has not had any adverse effect with respect to the diagnosis of vitamin $\mathrm{B}_{12}$ deficiency since its introduction over 10 years ago in the $\mathrm{US}^{(16,17)}$, one recent study from the post-fortification era showed that among older American adults with a low vitamin $\mathrm{B}_{12}$ status, a higher serum folate concentration was associated with an increased risk of cognitive impairment ${ }^{(18)}$. Regardless of whether mandatory fortification with FA goes ahead in European countries, however, preventing the high prevalence of low vitamin $\mathrm{B}_{12}$ status due to food-bound malabsorption among older adults is an important public health issue that needs to be addressed.

\section{Riboflavin}

Riboflavin is the precursor of the coenzymes flavin mononucleotide (FMN) and flavin adenine dinucleotide (FAD), both of which are essential for several reduction-oxidation enzymes. Classical riboflavin deficiency (presenting as angular stomatitis, cheilosis and glossitis) rarely occurs in isolation and usually occurs in association with other vitamin deficiencies ${ }^{(19)}$. Riboflavin status is determined by erythrocyte glutathione reductase activation coefficient (EGRac). This is a functional assay which measures the activity of glutathione reductase before and after in vitro reactivation with its prosthetic group $\mathrm{FAD}^{(20)}$. EGRac is calculated as a ratio of FAD-stimulated to unstimulated enzyme activity, with values of 1.3 or more generally indicative of suboptimal riboflavin status. Advantages of EGRac include stability and high sensitivity to small degrees of cofactor desaturation. The UK COMA Panel on Dietary Reference Values ${ }^{(21)}$ decided to base RNI values for riboflavin $(1.3 \mathrm{mg} / \mathrm{d}$ for men and $1.1 \mathrm{mg} / \mathrm{d}$ for women) on those intakes at which all but two corresponding EGRac results were less than 1.3 in British adult survey data available at that time ${ }^{(22)}$. Similarly, in the US, the relevant Committee ${ }^{(2)}$ used evidence from intake studies showing normal EGRac values when setting its reference values.

More recently, however, the Scientific Advisory Committee on Nutrition has expressed particular concern about the high proportion of the UK adult population with apparently poor riboflavin status as determined by EGRac values. In the National Diet \& Nutrition Survey (NDNS), a major proportion of adults were found to have abnormal $(>1.3)$ EGRac: $82 \%$ of men aged 19 to 24 years decreasing to $54 \%$ in those aged 50 to 64 years; $77 \%$ of women in the youngest age group decreasing to $50 \%$ in the oldest age group $^{(23)}$. Some would argue that these abnormal EGRac values are simply a characteristic of the sensitivity of the assay procedure used, as in general, they did not correspond with dietary data, which indicated that only $3 \%$ of men and $8 \%$ of women had a riboflavin intake below the lower reference nutrient intake (LRNI) value of $0.8 \mathrm{mg} / \mathrm{d}^{(13)}$. However, the NDNS shows some evidence of low intakes in young adults, particularly young women, with some $15 \%$ of women aged 19 to 24 years having a mean intake of riboflavin below the LRNI ${ }^{(13)}$. Consistent with NDNS findings, a recent study in Northern Ireland (Table 1) showed generally poor riboflavin status, and again particularly so among younger women.

Whether there is a general problem of poor riboflavin status in the UK population, as indicated by the large proportion with high EGRac values, is unclear and requires further investigation. Although EGRac is well established as a valid (often considered gold-standard) marker of riboflavin status, its measurement requires very specific treatment at the time of sampling and is therefore limited to those studies which have set out to measure EGRac. It does not enable riboflavin status to be determined retrospectively in large clinical studies which may have available a stored plasma sample, for example, on which $\mathrm{B}_{2}$ vitamers can be directly measured ${ }^{(24)}$.

\section{B-vitamin status and disease prevention}

\section{Neural tube defects (NTDs)}

NTDs are major malformations in which there is a failure of the neural tube to close properly. Importantly, the neural tube normally closes in the first few weeks of pregnancy and therefore the NTD malformations may have occurred before a woman even knows that she is pregnant. Folate has a well established protective role against both first occurrence and recurrence of NTDs, resulting in clear recommendations in the UK and elsewhere which have been in place for over 15 years. For the prevention of first occurrence of NTD (i.e. primary prevention), official bodies worldwide recommend women to take an additional $400 \mu \mathrm{g} / \mathrm{d}$ folate/FA from before conception up to the 12th gestational week. However, the achievement of this recommendation is proving to be very problematic in practice. Compliance with FA supplements is poor ${ }^{(25)}$ and consequently they are generally ineffective. Recent evidence shows that current recommendations have not had any measurable impact

Table 1. Homocysteine and related B-vitamin status in the UK: comparison of data from a convenience sample in Northern Ireland (NI) ${ }^{\star}$ and the National Diet and Nutrition Survey (NDNS) of British adults aged 19-64 years $†$

\begin{tabular}{|c|c|c|c|c|}
\hline & NI sample: males $19-64$ y $(n=215)$ & NDNS males $19-64$ y & NI sample: females $19-64$ y $(n=220)$ & NDNS females $19-64$ y \\
\hline tHcy $(\mu \mathrm{mol} / \mathrm{l})$ & $10.5 \pm 4.6$ & $11 \cdot 7 \pm 4 \cdot 6$ & $9 \cdot 6 \pm 2 \cdot 7$ & $10 \cdot 1 \pm 4 \cdot 8$ \\
\hline $\mathrm{SF}(\mathrm{nmol} / \mathrm{l})$ & $25 \cdot 0 \pm 14 \cdot 8$ & $20 \cdot 8 \pm 8 \cdot 6$ & $24 \cdot 1 \pm 15 \cdot 2$ & $22 \cdot 1 \pm 9.5$ \\
\hline $\mathrm{RCF}(\mathrm{nmol} / \mathrm{l})$ & $905 \pm 360$ & $694 \pm 288$ & $867 \pm 335$ & $685 \pm 293$ \\
\hline $\mathrm{B}_{12}(\mathrm{pmol} / \mathrm{l})$ & $270 \pm 97$ & $298 \pm 123$ & $278 \pm 108$ & $288 \pm 185$ \\
\hline EGRac & $1.35 \pm 0.15$ & $1.38 \pm 0.17$ & $1.39 \pm 0.18$ & $1.40 \pm 0.19$ \\
\hline
\end{tabular}

Values are presented as mean \pm SD.

Abbreviations: tHcy, plasma total homoysteine; SF, serum folate; RCF, red cell folate; $B_{12}$, serum vitamin $B_{12}$; and EGRac, erythrocyte glutathione reductase activation coefficient, a functional indicator of riboflavin status. A higher EGRac ratio indicates lower riboflavin status (values $\geq 1.3$ considered to indicate sub-optimal status).

*Adapted from Hoey et al. ${ }^{(54)}$.

†Ruston et al. ${ }^{(23)}$ 
on the rates of NTDs in some 13 European countries (including the UK) over a 10-year period, before and after the recommendations were introduced ${ }^{(26)}$. In contrast, the population-based policy of mandatory FA fortification of cereal grains implemented in North America and some non-European countries has substantially increased folate status ${ }^{(27)}$ and reduced the occurrence of NTDs ${ }^{(28,29)}$. Despite this evidence, many governments elsewhere have decided against implementing similar population-based policies because of safety concerns regarding chronic exposure to FA.

\section{Cardiovascular disease}

There is considerable interest in plasma homocysteine as a cardiovascular disease (CVD) risk factor, with meta-analyses of prospective studies predicting that lowering concentrations by $3(\mathrm{~mol} / \mathrm{l}$ (i.e. a $25 \%$ reduction in current levels) would reduce the risk of heart disease by up to $16 \%$ and stroke by up to $24 \%^{(30,31)}$. Good evidence for a causal relationship between elevated homocysteine and CVD comes from genetic studies. The most important genetic determinant of homocysteine in the general population is the common $677 \mathrm{C} \rightarrow \mathrm{T}$ variant in the gene coding for the folate-metabolising enzyme MTHFR which results in impaired folate metabolism and higher homocysteine concentrations in vivo ${ }^{(32)}$. Importantly, people with the homozygous mutant (TT) genotype (typically $10 \%$ of Western populations) $)^{(33)}$ are found to have a significantly higher CVD risk (by 14 to $21 \%$ ) compared to those without this genetic factor ${ }^{(34,35)}$.

A recent population based study showed that the decline in stroke-related mortality in recent years in the US and Canada related to the introduction of mandatory FA fortification ${ }^{(36)}$. Although the secondary prevention trials published to date have failed to confirm a benefit of homocysteine-lowering therapy on CVD events generally, they are now widely recognised as being substantially underpowered to detect a significant effect for heart disease risk, and therefore cannot be interpreted as evidence that no relationship exists. In support of this, evidence just published from a meta-analysis of clinical trials showed that homocysteine-lowering (by FA) reduced the risk of stroke by $18 \%$ overall and by $25 \%$ in those trials in people without a history of stroke ${ }^{(37)}$. Thus, although primarily aimed at reducing NTD, FA fortification may have an important role in the primary prevention of CVD, in particular stroke, via homocysteine-lowering.

\section{Cancer}

Folate is thought to play an important role in cancer prevention, with epidemiological evidence consistently showing inverse relationships between higher folate intakes and a reduced risk of cancer, most notably colorectal, but also pancreatic and breast cancer ${ }^{(38,39)}$. These observational studies from humans are substantiated by animal and experimental studies, with the latter focusing on the mechanisms explaining the possible cancer-preventative properties of folate. These have been attributed to its function in the de novo synthesis of thymidylate and purines, nucleotides required for DNA replication and repair. Folate is also required for the production of S-adenosylmethionine a universal donor of methyl groups for numerous methylation reactions including the methylation of DNA which is central to gene silencing. In addition, genetic studies show that polymorphisms in folate metabolism are important in influencing folate status, related one-carbon metabolism and cancer risk ${ }^{(38)}$.

Of note, the issue of folate and cancer has received much recent public health and scientific attention as a result of the publication of a randomised controlled trial which provided preliminary evidence, though as yet unconfirmed, suggesting that exposure to high dose FA ( $1 \mathrm{mg} / \mathrm{d}$ for 5 years) could promote colorectal tumorigenesis specifically in patients with preexisting neoplasms ${ }^{(40)}$. This in turn supports the view that FA might have a dual role in carcinogenesis: it might be protective before any precancerous lesions have developed and in populations with low folate status, whereas at high doses it might stimulate the further development of existing lesions in populations already exposed to high FA intakes (through fortification and supplementation). Thus the role of folate in carcinogenesis may be more complicated than the observational studies suggest; the timing, and particularly the dose of FA, appear to be highly relevant.

\section{Cognitive impairment}

Impaired cognitive function is a common problem of ageing, ranging in severity from mild memory loss to dementia, the latter characterised by a decline in memory and thinking to a level that impairs activities of daily living. Recent interest has focussed on the potential role of homocysteine related B-vitamins in maintaining cognitive function in ageing. Observational studies in both healthy and cognitively impaired older adults show that lower status of B-vitamins and/or higher homocysteine is associated with poorer cognitive function. However, it is difficult to interpret much of the evidence from observational studies, since poor diet may be both a cause and a consequence of poor cognitive function. Evidence from randomised trials of homocysteine-lowering with B-vitamins is lacking and inconclusive, with many of the studies in this area being of insufficient duration or sample size. Two well designed, randomised placebo-controlled trials of relatively long duration in older adults were recently published, but their findings are conflicting. One trial reported no benefit of B-vitamins (FA, vitamin $\mathrm{B}_{12}$ and vitamin $\mathrm{B}_{6}$ for two years) on cognitive performance ${ }^{(41)}$, whereas the other concluded that supplementation with FA for three years significantly improved cognitive function ${ }^{(42)}$. Further evidence is required to confirm whether optimal B-vitamin status has a role in preventing cognitive impairment or dementia.

\section{Osteoporosis}

In recent years evidence is emerging from large cohort studies in the USA, the Netherlands and Norway linking elevated homocysteine levels (and/or lower status of related B-vitamins) to lower bone mineral density and a higher rate of osteoporotic fracture. More convincing evidence is provided by a randomised trial showing that combined treatment with $\mathrm{FA}$ and vitamin $\mathrm{B}_{12}$ was effective in reducing the risk of hip fracture following stroke ${ }^{(43)}$, offering considerable support for the hypothesis that folate and/or vitamin $\mathrm{B}_{12}$ may delay the progression of osteoporosis, or that high homocysteine levels may promote it. If the link between elevated homocysteine and osteoporosis is 
confirmed as being a causative one, there is considerable scope for prevention of bone disease by lowering homocysteine through enhanced B-vitamin status.

\section{Homocysteine as a functional biomarker of B-vitamin status}

Apart from its potential role as a risk factor in CVD and other diseases, plasma homocysteine is very responsive to intervention with the B-vitamins required for its metabolism: folate ${ }^{(44)}$, and to a lesser extent, vitamin $\mathrm{B}_{12}{ }^{(45)}$, vitamin $\mathrm{B}_{6}^{(46)}$ and riboflavin ${ }^{(47)}$. A recent meta-analysis of intervention studies examining the effect of B-vitamins on homocysteinelowering, showed that vitamin $\mathrm{B}_{12}$ produces an additional one-third $(7 \%)$ lowering of homocysteine, over and above that achieved with FA alone (typically $20-25 \%$ lowering) ${ }^{(48)}$. Thus vitamin $\mathrm{B}_{12}$ is generally considered to be a far less effective determinant of homocysteine concentrations compared with folate. However, evidence from a study in healthy subjects, supplemented with low dose $\mathrm{FA}^{(49)}$, and from studies in the era of mandatory FA fortification of cereal grains in the $\mathrm{US}^{(50)}$, shows that vitamin $\mathrm{B}_{12}$ becomes the main nutritional determinant of homocysteine once folate status is optimised.

The typical phenotype associated with homozygosity (TT genotype) for the MTHFR $677 \mathrm{C} \rightarrow \mathrm{T}$ polymorphism is elevated homocysteine levels ${ }^{(32)}$. Individuals with the TT genotype are considered to have increased dietary folate requirements on the basis that they have lower red cell folate levels compared to those without this genetic variant ${ }^{(51)}$, and the expected increase in homocysteine is found to be most marked among those with lower folate status ${ }^{(52)}$. Apart from folate, however, riboflavin (FAD) is required as a cofactor for the MTHFR enzyme. The reduced activity of the variant form of MTHFR has been shown in vitro to result from the inappropriate loss of its FAD cofactor ${ }^{(53)}$. Recent results, showing a genotype-specific response of homocysteine to riboflavin supplementation, now confirm that riboflavin is an independent modifier of homocysteine in people with the TT genotype. Significant lowering of homocysteine in response to riboflavin supplementation was observed in healthy individuals with the TT genotype, with levels decreasing by as much as $22 \%$ overall, and markedly so (by $40 \%$ ) in those with lower riboflavin status at baseline ${ }^{(47)}$. No homocysteine response to intervention was observed in non-homozygous individuals (CC or CT genotypes), despite a significant improvement in riboflavin status and the pre-selection of subjects with sub-optimal riboflavin status at baseline. The responsiveness of homocysteine to riboflavin is therefore specific to individuals with the MTHFR 677 TT genotype and represents a new gene-nutrient interaction.

Thus homocysteine can be considered a reliable functional marker of the status of folate in particular, of vitamin $B_{12}$ in those optimised in folate, and of riboflavin specifically in those with the MTHFR 677 TT genotype.

\section{Public health challenges in achieving optimal B-vitamin} status

Optimal folate status has an established role in preventing NTDs and possible preventative roles in stroke and other diseases. Thus, the achievement of optimal folate status should be a priority for public health, but will only be achieved with levels of intake of the vitamin greater than those currently provided by a typical diet as eaten in most European countries. Strategies to increase folate status are generally ineffective if based on health promotion and educational campaigns, and are controversial if based on mandatory fortification of foods with FA. There is a particular challenge for some European and other populations without access to fortified foods (not even on a voluntary basis in some cases) who are therefore dependent on natural food folate sources. In the case of vitamin $\mathrm{B}_{12}$, the achievement of an optimal status may present a particular difficulty for many older people because of the common problem of agerelated food-bound $\mathrm{B}_{12}$ malabsorption. Finally, the evidence that riboflavin status is generally low in the UK population, and particularly so in younger women, warrants further investigation.

\section{References}

1. McNulty H \& Pentieva K (2004) Folate bioavailability. Proc Nutr Soc 63, 529-536.

2. Institute of Medicine, Panel on Folate, Other B Vitamins, and Choline (1998) Dietary Reference Intake; Thiamine, Riboflavin, Niacin, Vitamin $B_{6}$, Folate, Vitamin $B_{12}$, Pantothenic Acid, Biotin, and Choline. Washington, DC: National Academy Press.

3. Sauberlich HE, Kretsch MJ, Skala JH, Johnson HL \& Taylor RC (1987) Folate requirement and metabolism in nonpregnant women. Am J Clin Nutr 46, 1016-1028.

4. Pfeiffer CM, Rogers LM, Bailey LB \& Gregory JF (1997) Absorption of folate from fortified cereal-grain products and of supplemental folate consumed with or without food determined by using a dual-label stable-isotope protocol. Am J Clin Nutr 66, 1388-1397.

5. Hannon-Fletcher MP, Armstrong NC, Scott JM, et al. (2004) Determination of the bioavailability of food folates in a controlled intervention study. Am J Clin Nutr 80, 911-918.

6. Winkels RM, Brouwer IA, Siebelink E, Katan MB \& Verhoef P (2007) Bioavailability of food folates is $80 \%$ of that of folic acid. Am J Clin Nutr 85, 465-473.

7. Miller JW, Garrod MG, Rockwood AL, Kushnir MM, Allen LH, Haan MN \& Green R (2006) Measurement of total vitamin $B_{12}$ and holotranscobalamin, singly and in combination, in screening for metabolic vitamin $\mathrm{B}_{12}$ deficiency. Clin Chem 52, 278-285.

8. Ueland PM, Eilertsen I, Quadros EV, Rothenberg SP, Fedosov SN, Sundrehagen E \& Orning L (2002) Direct assay for cobalamin bound to transcobalamin (holo-transcobalamin) in serum. Clin Chem 48, 526-532.

9. Morkbak AL, Heimdal RM, Emmens K, Molloy A, Hvas AM, Schneede J, Clarke R, Scott JM, Ueland PM \& Nexo E (2005) Evaluation of the technical performance of novel holotranscobalamin (holoTC) assays in a multicenter European demonstration project. Clin Chem Lab Med 43, 1058-1064.

10. Hvas AM \& Nexo E (2005) Holotranscobalamin - a first choice assay for diagnosing early vitamin B deficiency? J Intern Med 257, 289-298.

11. Clarke R, Refsum H, Birks J, et al. (2003) Screening for vitamin B-12 and folate deficiency in older persons. Am J Clin Nutr 77, $1241-1247$.

12. Wolters M, Strohle A \& Hahn A (2004) Cobalamin: a critical vitamin in the elderly. Prev Med 39, 1256-1266.

13. Henderson L, Irving K, Gregory J, Bates CJ, Prentice A, Perks J, Swan G \& Farron M (2003) The National Diet and Nutrition Survey: Adults Aged 19 to 64 years. Volume 3: Vitamin and 
Mineral Intake and Urinary Analytes. London: The Stationery Office.

14. Carmel R (1997) Cobalamin, the stomach, and aging. Am J Clin Nutr 66, 750-759.

15. Dickinson CJ (1995) Does folic acid harm people with vitamin $\mathrm{B}_{12}$ deficiency? $Q J$ Med 88, 357-364.

16. Mills JL, Von Kohorn I, Conley MR, Zeller JA, Cox C, Williamson RE \& Dufour DR (2003) Low vitamin $B_{12}$ concentrations in patients without anemia: the effect of folic acid fortification of grain. Am J Clin Nutr 77, 1474-1477.

17. Liu S, West R, Randell E, et al. (2004) A comprehensive evaluation of food fortification with folic acid for the primary prevention of neural tube defects. BMC Pregnancy Childbirth 4, 20-29.

18. Morris MS, Jacques PF, Rosenberg IH \& Selhub J (2007) Folate and vitamin $B_{12}$ status in relation to anemia, macrocytosis, and cognitive impairment in older Americans in the age of folic acid fortification. Am J Clin Nutr 85, 193-200.

19. Gibson RS (2005) Assessment of the status of thiamin, riboflavin and niacin. In Principles of Nutritional Assessment, 2nd ed. pp. 545-574, New York: Oxford University Press.

20. Powers HJ, Bates CJ, Prentice AM, Lamb WH, Jepson M \& Bowman H (1983) The relative effectiveness of iron and iron with riboflavin in correcting a microcytic anaemia in men and children in rural Gambia. Hum Nutr Clin Nutr 37C, 413-425.

21. Department of Health (1991) Dietary Reference Values for Food, Energy and Nutrients for the United Kingdom. London: The Stationery Office.

22. Gregory J, Foster K, Tyler H \& Wiseman M (1990) The Dietary and Nutritional Survey of British Adults. London: The Stationery Office.

23. Ruston D, Hoare J, Henderson L, Gregory J, Bates CJ, Prentice A, Birch M, Swan G \& Farron M (2004) The National Diet and Nutrition Survey: Adults Aged 19 to 64 years. Volume 4: Nutritional Status (Anthropometry and Blood Analytes), Blood Pressure and Physical Activity. London: The Stationery Office.

24. Hustad S, McKinley M, McNulty H, Schneede J, Strain JJ, Scott JM \& Ueland PM (2002) Riboflavin, flavin mononucleotide, and flavin adenine dinucleotide in human plasma and erythryocytes at baseline and after low-dose riboflavin supplementation. Clin Chem 48, 1571-1577.

25. Eichholzer M, Tonz O \& Zimmermann R (2006) Folic acid: a public-health challenge. Lancet 367, 1352-1361.

26. Botto LD, Lisi A, Robert-Gnansia E, et al. (2005) International retrospective cohort study of neural tube defects in relation to folic acid recommendations: are the recommendations working? BMJ 330, 571-576.

27. Pfeiffer CM, Caudill SP, Gunter EW, Osterloh J \& Sampson EJ (2005) Biochemical indicators of B vitamin status in the US population after folic acid fortification: results from the National Health and Nutrition Examination Survey 1999-2000. Am J Clin Nutr 82, 442-450.

28. Honein MA, Paulozzi LJ, Mathews TJ, Erickson JD \& Wong L-YC (2001) Impact of folic acid fortification of the US food supply on the occurrence of neural tube defects. JAMA $\mathbf{2 8 5}$, 2981-2986.

29. De Wals P, Tairou F, Van Allen MI, et al. (2007) Reduction in neural-tube defects after folic acid fortification in Canada. $N$ Engl J Med 357, 135-142.

30. Homocysteine Studies Collaboration (2002) Homocysteine and risk of ischemic heart disease and stroke. JAMA $\mathbf{2 8 8}$, $2015-2022$.

31. Wald DS, Law M \& Morris JK (2002) Homocysteine and cardiovascular disease: evidence on causality from a meta-analysis. BMJ 325, 1202-1208.
32. Frosst P, Blom HJ, Milos R, et al. (1995) A candidate genetic risk factor for vascular disease: a common mutation in methylenetetrahydrofolate reductase. Nat Genet 10, 111-113.

33. Wilcken B, Bamforth F, Li Z, et al. (2003) Geographical and ethnic variation of the $677 \mathrm{C}>\mathrm{T}$ allele of 5,10 methylenetetrahydrofolate reductase (MTHFR): findings from over 7000 newborns from 16 areas world wide. J Med Genet 40, 619-625.

34. Klerk M, Verhoef P, Clarke R, Blom HJ, Kok FJ \& Schouten EG (2003) MTHFR 677C > T polymorphism and risk of coronary heart disease: a meta-analysis. JAMA 288, 2023-2031.

35. Lewis SJ, Ebrahim S \& Davey Smith G (2005) Meta-analysis of MTHFR $677 \mathrm{C} \rightarrow \mathrm{T}$ polymorphism and coronary heart disease: does totality of evidence support causal role for homocysteine and preventive potential of folate. BMJ 331, 1053-1056.

36. Yang Q, Botto LD, Erickson JD, Berry RJ, Sambell C, Johansen H \& Friedman JM (2006) Improvement in stroke mortality in Canada and the United States, 1990 to 2002. Circulation 113, $1335-1343$.

37. Wang X, Qin X, Demirtas H, Li J, Mao G, Huo Y, Sun N, Liu L \& Xu X (2007) Efficacy of folic acid supplementation in stroke prevention: a meta-analysis. Lancet 369, 1876-1882.

38. Giovannucci E (2002) Epidemiologic studies of folate and colorectal neoplasia: a review. J Nutr 132, Suppl., 2350S-2355S.

39. Ericson U, et al. (2007) High folate intake is associated with lower breast cancer incidence in postmenopausal women in the Malmo Diet and Cancer cohort. Am J Clin Nutr 86, 434-443.

40. Cole BF, Baron JA, Sandler RS, et al. (2007) Folic acid for the prevention of colorectal adenomas: a randomized clinical trial. JAMA 297, 2351-2359.

41. McMahon JA, Green TJ, Skeaff CM, Knight RG, Mann JI \& Williams SM (2006) A controlled trial of homocysteine lowering and cognitive performance. $N$ Engl J Med 354, 2764-2772

42. Durga J, van Boxtel MP, Schouten EG, Kok FJ, Jolles J, Katan MB \& Verhoef P (2007) Effect of 3-year folic acid supplementation on cognitive function in older adults in the FACIT trial: a randomised, double blind, controlled trial. Lancet 369, 208-216.

43. Sato Y, Honda Y, Iwamoto J, Kanoko T \& Satoh K (2005) Effect of folate and mecobalamin on hip fractures in patients with stroke: a randomized controlled trial. JAMA 293, $1082-1088$.

44. Homocysteine Lowering Trialists' Collaboration (1998) Lowering blood homocysteine with folic acid based supplements: meta-analysis of randomized trials. BMJ 316, 894-898.

45. Eussen SJPM, de Groot LCPGM, Clarke R, et al. (2005) Oral cyanocobalamin supplementation in older people with vitamin $\mathrm{B}_{12}$ deficiency. A dose finding trial. Arch Intern Med 165, $1167-1172$.

46. McKinley MC, McNulty H, McPartlin J, et al. (2001) Low-dose vitamin $\mathrm{B}_{6}$ effectively lowers fasting plasma homocysteine in healthy elderly persons who are folate and riboflavin replete. Am J Clin Nutr 73, 759-764.

47. McNulty H, Dowey LC, Strain JJ, Dunne A, Ward M, Molloy AM, McAnena LB, Hughes JP, Hannon-Fletcher M \& Scott JM (2006) Riboflavin lowers homocysteine in individuals homozygous for the MTHFR $677 \mathrm{C} \rightarrow \mathrm{T}$ polymorphism. Circulation 113, 74-80.

48. Homocysteine Lowering Trialists' Collaboration (2005) Dosedependant effects of folic acid on blood concentrations of homocysteine: a meta-analysis of the randomized trials. Am J Clin Nutr 82, 806-812.

49. Quinlivan EP, McPartlin J, McNulty H, Ward M, Strain JJ, Weir DG \& Scott JM (2002) Importance of both folic acid and vitamin B-12 in reduction of risk of vascular disease. Lancet 359, $227-228$.

50. Liaugaudas G, Jacques PF, Selhub J, Rosenberg IH \& Boston AG (2001) Renal insufficiency, vitamin B-12 status, and population 
attributable risk for mild hyperhomocysteinemia among coronary artery disease patients in the era of folic acid-fortified cereal grain flour. Arterioscler Thromb Vasc Biol 21, 849-851.

51. Molloy AM, Daly S, Mills JL, Kirke PN, Whitehead AS, Ramsbottom D, Conley MR, Weir DG \& Scott JM (1997) Thermolabile variant of 5,10-methylenetetrahydrofolate reductase associated with low red-cell folates: implications for folate intake recommendations. Lancet 349, 1591-1593.

52. Jacques PF, Bostom AG, Williams RR, Ellison RC, Eckfeldt JH, Rosenberg IH, Selhub J \& Rozen R (1996) Relation between folate status, a common mutation in methylenetetrahydrofolate reductase, and plasma homocysteine concentrations. Circulation 93, 7-9.

53. Yamada K, Chen Z, Rozen R \& Matthews RG (2001) Effects of common polymorphisms on the properties of recombinant human methylenetetrahydrofolate reductase. Proc Natl Acad Sci U S A 98, 14853-14858.

54. Hoey L, McNulty H, Askin N, Dunne A, Ward M, Pentieva K, Strain JJ, Molloy AM, Flynn C \& Scott JM (2007) Impact of a voluntary food fortification policy on folate, related B-vitamin status and homocysteine in healthy adults. Am J Clin Nutr 86, $1405-1413$. 